\title{
PENGARUH JOB INSECURITY DAN WORKPLACE BULLYING TERHADAP TURNOVER INTENTION KARYAWAN SEMINYAK GARDEN HOTEL \& POOL
}

\author{
Ni Luh Gede Yuliani ${ }^{1}$ \\ AA Ngurah Sadiartha ${ }^{2}$ \\ Putu Krisna Adwitya Sanjaya ${ }^{3}$ \\ ${ }^{1,2,3}$ Fakultas Ekonomi, Bisnis, dan Pariwisata Universitas Hindu Indonesia \\ Email : luhde.yuliani123@gmail.com
}

\begin{tabular}{|l|l|l|}
\hline Diterima: 2 Desember 2020 & Direvisi: 8 Desember 2020 & Disetujui: 20 Desember 2020
\end{tabular}

\begin{abstract}
Turnover intention is an employee's desire to leave the organization that has not been manifested in a definite action by leaving the organization where the employee is located. The purpose of this study was to determine the effect of job insecurity and workplace bullying on employee turnover intention at the Seminyak Garden Hotel \& Pool. This research was conducted at Seminyak Garden Hotel \& Pool which is located on Jalan Raya Petitenget No.7, Kerobokan, Kuta Bali. The number of respondents taken was 47 employees with saturated sampling method. Data collection was carried out through observation, questionnaires, interviews, literature and documentation. The data analysis techniques used were validity and reliability tests, classical assumption tests, multiple linear regression analysis, determination, $t$ test (partial regression), and $F$ test (simultaneous regression). Based on the analysis, it was found that Job Security has a positive and significant effect on Turnover Intention. Workplace Bullying has a positive and significant effect on Employee Turnover Intention. Job Insecurity and Workplace Bullying have a positive and significant effect on Employee Intention Turnover at Seminyak Garden Hotel \& Pool.
\end{abstract}

Keyword: turnover intention, job inserence, workplace bullying.

\begin{abstract}
ABSTRAK
Turnover intention merupakan keinginan seorang karyawan untuk meninggalkan organisasi yang belum diwujudkan dalam sebuah tindakan yang pasti dengan meninggalkan organisasi dimana karyawan berada. Tujuan penelitian ini adalah untuk mengetahui pengaruh job insecurity dan workplace bullying terhadap turnover intention karyawan pada Seminyak Garden Hotel \& Pool. Penelitian ini dilakukan pada Seminyak Garden Hotel \& Pool yang berlokasi di Jalan Raya Petitenget No.7,Kerobokan, Kuta Bali. Jumlah responden 47 karyawan (sampling jenuh). Pengumpulan data dilakukan melalui observasi, kuesioner, wawancara, kepustakaan dan dokumentasi. Teknik analisis data yang digunakan adalah uji validitas dan reliabilitas, uji asumsi klasik, analisis regresi linier berganda, determinasi, uji t (regresi parsial), dan uji F (regresi simultan). Hasil analisis ditemukan bahwa Job Inscecurity berpengaruh positif dan signifikan terhadap Turnover Intention. Workplace Bullying berpengaruh positif dan signifikan terhadap Turnover Intention. Job Inscecurity dan Workplace Bullying berpengaruh positif dan signifikan terhadap Turnover Intention pada Karyawan Seminyak Garden Hotel \& Pool.

Kata Kunci : turnover intention, job inserity, workplace bullying.
\end{abstract}




\section{Pendahuluan}

Sebagai destinasi wisata favorit di dunia, industri hotel di Bali saat ini berada dalam kondisi persaingan yang ketat sehingga setiap hotel harus memberikan pelayanan terbaik. Mengembangkan fasilitas hotel dan meningkatkan kualitas SDM merupakan strategi yang dapat ditempuh untuk menghadapi persaingan, karena pada dasarnya kualitas SDM atau kualitas karyawan berperan sangat penting dalam menentukan kinerja perusahaan dan cara yang dapat mendukung pencapaian tujuan tersebut adalah melalui peningkatan kinerja karyawan sehingga perusahaan perlu untuk mempertahankan sumber daya yang potensial agar tidak memiliki keinginan melakukan turnover.

Turnover intention karyawan dapat dilihat dari beberapa indikasi, yaitu : absen yang meningkat, mulai malas kerja, naiknya keberanian untuk melanggar tata tertib kerja, keberanian untuk menentang atau protes kepada atasan, perilaku positif yang sangat berbeda dari biasanya (Nasution, 2009). Tingginya tingkat turnover intention sering menjadi patokan yang sering digunakan sebagai indikasi adanymasalah mendasar pada sebuah perusahaan atau organisasi, ketidakstabilan suasana kerja yang kurang kondusif serta menyebabkan turunnya kinerja sumber daya manusia dalam sebuah perusahaan. Minanti et al., (2015) menyatakan banyak faktor yang dapat menyebabkan timbulnya turnover intention, salah satu faktornya adalah ketidakamanan kerja (job insecurity), yaitu situasi yang muncul ketika ada perbedaan antara harapan pekerja mengenai pekerjaannya, dan situasi actual mengenai pekerjaan itu sendiri (Adewale dan Adekiya, 2015). Penelitian yang dilakukan oleh Ismail (2015), Hanafiah (2014), dan Heryanda (2019) menunjukkan bahwa job insecurity berpengaruh signifikan terhadap turnover intention.

Selain job insecurity, yang dapat berpengaruh terhadap turnover intention karyawan adalah tindakan intimidasi atau bullying di tempat kerja. Menurut Galambek et al., (2014) intimidasi atau tindakan bullying di tempat kerja adalah proses dimana seorang karyawan sering mengalami tindakan negatif dengan intensitas minimal satu minggu satu kali dalam jangka waktu yang relatif lama (misalnya 6 bulan) oleh rekan-rekan atau atasan terhadap karyawan yang tidak memiliki kekuasaan formal maupun informal. Menurut Mete dan Sokmen (2016), bullying di tempat kerja meliputi situasi di mana seseorang mengalami penganiayaan di tempat kerja untuk waktu yang lama dan dia tidak memiliki kesempatan untuk membela dirinya. Workplace bullying adalah tentang serangan yang dipersonalisasi, sering berkelanjutan pada satu rekan oleh rekan lainnya menggunakan perilaku yang 
menghukum secara emosional dan psikologis (Oade, 2009 : 2), dan juga merupakan perilaku gigih, perilaku yang tidak diinginkan, ofensif, memalukan terhadap individu atau kelompok karyawan (Yahaya et al, 2012). Ocel et al (2012) dan Yahaya et al (2012) menunjukkan bahwa workplace bullying berpengaruh signifikan terhadap turnover intention karyawan.

Salah satu hotel yang berada di Bali, lebih tepatnya di Kerobokan, Kuta Bali, yaitu Seminyak Garden \& Pool dapat dikatakan memiliki tingkat turnover yang cukup tinggi. Turnover karyawan Seminyak Garden Hotel \& Pool paling tinggi terjadi pada bulan Maret dengan Valuntary Separation sebesar 5 orang dan dengan turnover rate sebesar 10,6\%. Permasalahan job insecurity di Seminyak Garden Hotel \& Pool yaitu sebagian karyawan merasa ketidakamanan kerja yang disebabkan oleh tugas-tugas yang didelegasikan bukan merupakan inti dari pekerjaan proyek seperti yang dialami seorang karyawan yang bertugas sebagai administrasi sering mengambil pekerjaan supervisor, sehingga seringa kali mengalami permasalahan ketidakjelasan peran dan tanggung jawab dalam melakukan pekerjaan. Workplace bullying yang terjadi di Seminyak Garden Hotel \& Pool adalah dalam bentuk bullying verbal, dimana bentuk pembulian hanya dengan kata-kata menghina dan menyindir seperti yang sering terjadi seorang karyawan yang lama menjadi daily worker tidak kunjung ada pengangkatan staff.

Masalah utama dalam industri perhotelan adalah tingginya tingkat turnover (Faldetta et al., 2013). Tingkat perputaran karyawan di industri perhotelan rata-rata sekitar 200\% hingga 300\% per tahun (Demir et al., 2007). Ketika seorang karyawan meninggalkan pekerjaannya, organisasi tidak hanya kehilangan sumber daya manusia tetapi juga menanggung biaya yang terkait dengan pergantian karyawan yang tinggi (Yang, 2008). Tingkat turnover karyawan yang tinggi meningkatkan biaya dan menyebabkan produktivitas negatif (Lam et al., 2002). Oleh karena itu, pergantian karyawan dianggap sebagai faktor negatif yang berdampak pada kualitas layanan, dan suasana hati karyawan serta profitabilitas dan kegiatan lainnya (Kim dan Jogaratnam, 2010). Tujuan penelitian ini adalah (1) mengetahui pengaruh job insecurity terhadap turnover intention karyawan, (2) mengetahui pengaruh workplace bullying terhadap turnover intention, dan (3) mengetahui pengaruh job insecurity dan workplace bullying terhadap turnover intention karyawan Seminyak Garden Hotel \& Pool.

\section{Telaah Literatur Dan Hipotesis}

\section{Telaah Literatur}

\section{Job Insecurity}

Menurut Suciati dkk.,(2015) job insecurity adalah ketidakberdayaan untuk mempertahankan kesinambungan yang diinginkan dalam kondisi kerja yang terancam. Job 
insecurity dikonseptualisasikan sebagai ketidakpastiandan kurangnya kontrol dari kelanjutan masa depan pekerjaan karyawan (Kekesi dan Collins, 2014). Kang el at (2012) menganggap ketidaknyaman kerja sebagai suatu kegelisahan yang dirasakan karyawan pada saat bekerja dimana mereka mereka dihadapkan pada kondisi yang tidak menyenangkan.

\section{Workplace Bullying}

Penindasan di tempat kerja adalah bentuk penganiayaan antarpribadi yang melampaui sekadar ketidaksopanan dan terdiri dari tindakan penghinaan yang disengaja dan berulang terhadap individu dan menciptakan lingkungan kerja yang menindas (Salin, 2003). Berthelsen et al. (2011) dalam Glambek et al. (2014) korban bullying di tempat kerja mungkin akan mengalami gangguan sehingga melakukan cuti sakit, rehabilitasi dan pensiun dini, atau mungkin memilih untuk berhenti secara sukarela karena sifat buruk dari kondisi kerja dimana intimidasi atau bullying terjadi. Bullying di tempat kerja berarti melecehkan, menyinggung, secara sosial mengeksklusikan seseorang atau secara negatif memengaruhi tugas-tugas pekerjaan seseorang. Agar label intimidasi diterapkan pada aktivitas, interaksi, atau proses tertentu, itu harus terjadi berulang-ulang dan secara teratur, misalnya mingguan dan melalui periode waktu misalnya sekitar enam bulan (Rai dan Agarwal (2016)

\section{Turnover Intention}

Turnover intention adalah niat untuk mengundurkan diri dari pekerjaan saat ini dan kecenderungan untuk mencari pekerjaan di organisasi/perusahaan lain (Emiroglu et al, 2015). Niat turnover dinyatakan sebagai kesadaran karyawan atau pemikiran tentang berhenti dari pekerjaan (Çelik dan Çıra, 2013) Akgunduz dan Eryilmaz (2018) mendefinisikan turnover intention sebagai kesadaran karyawan dan keinginan yang disengaja untuk meninggalkan organisasi tempat bekerja. Niat ini dapat diukur dengan keinginan karyawan untuk meninggalkan pekerjaan dan dengan sengaja mencari pekerjaan baru (Avcı dan Küçükusta, 2009).

\section{Hipotesis}

Berdasarkan telaah literatur dan kajian empiris yang telah dilakukan, maka hipotesis yang diajukan dalam penelitian ini antara lain :

H1 : Job insecurity berpengaruh positif dan signifikan terhadap turnover intention karyawan Seminyak Garden Hotel \& Pool.

$\mathrm{H} 2$ : Workplace bullying berpengaruh positif signifikan terhadap turnover intention karyawan Seminyak Garden Hotel dan Pool 
H3 : Job insecurity dan workplace bullying berpengaruh positif signifikan terhadap turnover intention karyawan pada Seminyak Garden Hotel \& Pool.

\section{Metode Penelitian}

\section{Desain Penelitian}

Penelitian ini menggunakan penelitian yang bersifat asosiatif dengan tujuan untuk mengetahui pengaruh atau hubungan antara tiga variabel, dengan job insecurity dan workplace bullying sebagai variabel eksogen, turnover intention sebagai variabel endogen. Kerangka berpikir penelitian ini dpat dilihat pada Gambar 3.1 berikut ini :

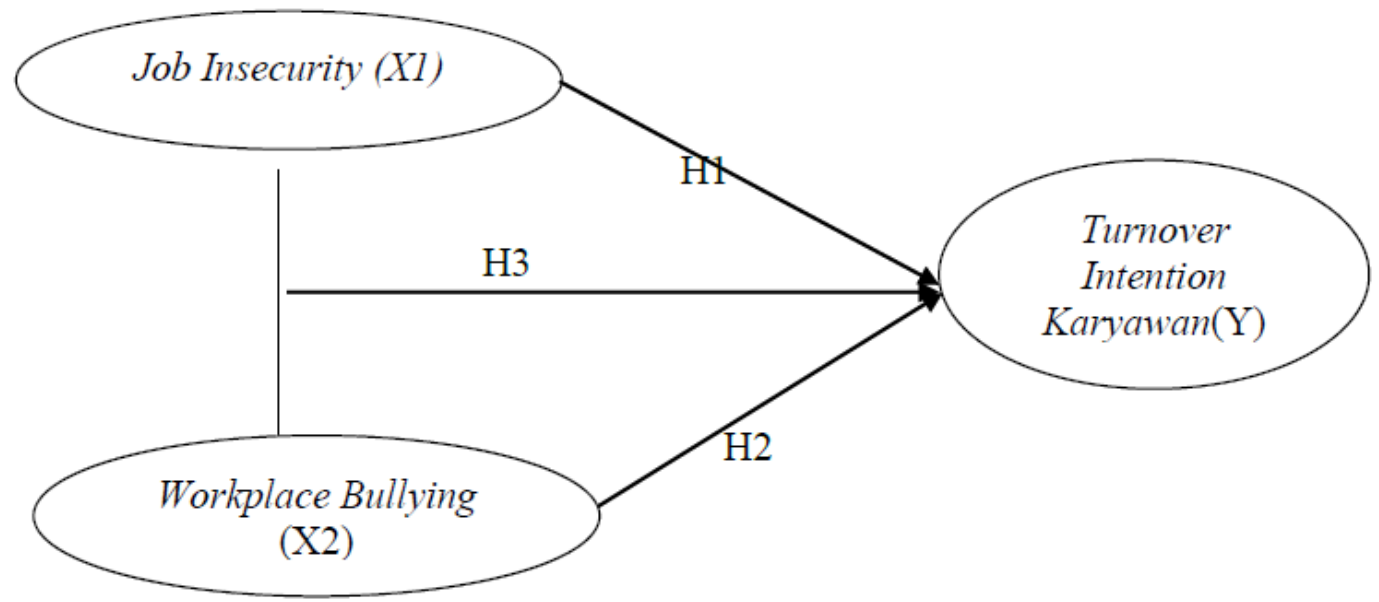

Gambar 3.1

Pengaruh Job Insecurity dan workplace bullying terhadap Turnover Intention Karyawan Seminyak Garden Hotel \& Pool

\section{Populasi dan Sampel}

Populasi dalam penelitian ini karyawan Seminyak Garden Hotel \& Pool yang totalnya berjumlah 47 orang, dengan demikian maka seluruh populasi dalam penelitian ini dilibatkan sebagai responden, sehingga penelitian ini menggunakan metode sensus yang artinya seluruh populasi dilibatkan dalam penelitian.

\section{Metode Pengumpulan Data}

Penelitian ini menggunakan metode pengumpulan data antara lain observasi, wawancara, studi pustaka, dokumentasi, dan kuisioner. Pada metode kuisioner menggunakan Skala Likert yang terdiri atas 5 (lima) pilihan jawaban yaitu sangat yidak setuju diberi bobot 1 , tidak setuju diberi bobot 2 , cukup setuju diberi bobot 3 , setuju dioberi bobot 4 , dan sangat setuju diberi bobot 5 .

\section{Teknik Analisis Data}

1. Uji instrumen penelitian dilakukan dengan melakukan uji validitas dan reliabilitas. Uji validitas dilakukan untuk mengukur sah atau tidaknya suatu kuisioner serta seberapa kuat 
hubungan suatu variabel dengan variabel lainnya, sedangkan uji reliabilitas dilakukan untuk mengukur konsistensi variabel penelitian. uji validitas dan reliabilitas dalam penelitian ini dilakukan dnegan menggunakan software SPSS.

2. Uji asumsi klasik, dilakukan dengan uji normalitas, uji multikolinearitas, dan uji heteroskedastisitas.

3. Analisis regresi linier berganda, yaitu model regresi linear dengan melibatkan lebih dari satu variabel bebas atau predictor. Uji regresi linear berganda dilakukan untuk menguji hipotesis 1 dan hipotesis 2 dengan menggunakan uji t, dan menguji hipotesis 3 dengan menggunakan uji F.

4. Uji determinasi, dilakukan untuk mengetahui besarnya pengaruh variabel bebas terhadap terikat dalam satuan persen $(\%)$.

\section{Hasil dan Pembahasan}

\section{Uji Validitas}

Tabel 1.

Hasil Uji Validitas dan Reliabilitas

\begin{tabular}{|c|c|c|c|}
\hline \multicolumn{4}{|c|}{ Variabel Job Inscecurity } \\
\hline No & Indikator & Koefisien Korelasi & Keterangan \\
\hline 1 & $\mathrm{X} 1.1$ & 0,931 & Valid \\
\hline 2 & $\mathrm{X} 1.2$ & 0,918 & Valid \\
\hline 3 & $\mathrm{X} 1.3$ & 0,938 & Valid \\
\hline 4 & $\mathrm{X} 1.4$ & 0,972 & Valid \\
\hline 5 & $\mathrm{X} 1.5$ & 0,916 & Valid \\
\hline 6 & $\mathrm{X} 1.6$ & 0,938 & Valid \\
\hline 7 & $\mathrm{X} 1.7$ & 0,944 & Valid \\
\hline 8 & $\mathrm{X} 1.8$ & 0,945 & Valid \\
\hline 9 & $\mathrm{X} 1.9$ & 0,900 & Valid \\
\hline 10 & $\mathrm{X} 1.10$ & 0,954 & Valid \\
\hline 11 & $\mathrm{X} 1.11$ & 0,844 & Valid \\
\hline 12 & $\mathrm{X} 1.12$ & 0,958 & Valid \\
\hline 13 & $\mathrm{X} 1.13$ & 0,428 & Valid \\
\hline \multicolumn{4}{|c|}{ Variabel Workplace Bullying } \\
\hline No & Indikator & Koefisien Korelasi & Keterangan \\
\hline 1 & $\mathrm{X} 2.1$ & 0,839 & Valid \\
\hline 2 & $\mathrm{X} 2.2$ & 0,884 & Valid \\
\hline 3 & $\mathrm{X} 2.3$ & 0,758 & Valid \\
\hline 4 & $\mathrm{X} 2.4$ & 0,766 & Valid \\
\hline 5 & $\mathrm{X} 2.5$ & 0,783 & Valid \\
\hline 6 & $\mathrm{X} 2.6$ & 0,700 & Valid \\
\hline 7 & $\mathrm{X} 2.7$ & 0,775 & Valid \\
\hline 8 & $\mathrm{X} 2.8$ & 0,786 & Valid \\
\hline 9 & $\mathrm{X} 2.9$ & 0,870 & Valid \\
\hline 10 & $\mathrm{X} 2.10$ & 0,819 & Valid \\
\hline \multicolumn{4}{|c|}{ Variabel Turnover Intention Karyawan } \\
\hline No & Indikator & Koefisien Korelasi & Keterangan \\
\hline 1 & Y.1 & 0,719 & Valid \\
\hline 2 & Y.2 & 0,847 & Valid \\
\hline 3 & Y.3 & 0,897 & Valid \\
\hline 4 & Y.4 & 0,854 & Valid \\
\hline 5 & Y.5 & 0,915 & Valid \\
\hline
\end{tabular}

Sumber : data primer, diolah (2019) 
Uji validitas dalam penelitian ini dilakukan dengan menggunakan program SPSS versi 23.0. Hasil uji disajikan pada Tabel 1. Berdasarkan Tabel 1 maka dapat dikatakan seluruh item pernyataan memiliki koefisien korelasi $>0,30$ sehingga seluruh item pernyataan adalah valid

Hasil uji menunjukkan nilai cronbach alpha lebih besar dari 0,60 sehingga dapat dikatakan bahwa semua variabel adalah reliabel.

Tabel 2

Hasil Uji Reliabilitas

\begin{tabular}{|c|l|c|c|}
\hline No & \multicolumn{1}{|c|}{ Variabel } & $\begin{array}{c}\text { Koefisien } \\
\text { Korelasi }\end{array}$ & Keterangan \\
\hline 1 & Job Inscecurity & 0,980 & Reliabel \\
\hline 2 & Workplace Bullying & 0,935 & Reliabel \\
\hline 3 & Turnover Intention Karyawan & 0,898 & Reliabel \\
\hline
\end{tabular}

Sumber : data primer, diolah (2019)

\section{Deskripsi Jawaban Responden}

Tabel 3.

Kriteria dan Penilaian Jawaban Responden Terhadap Variabel Job Insecurity

\begin{tabular}{|c|c|c|c|c|c|c|c|c|c|}
\hline \multirow{2}{*}{\multicolumn{2}{|c|}{ Pernyataan }} & \multicolumn{5}{|c|}{ Jawaban } & \multirow{3}{*}{$\begin{array}{c}\begin{array}{c}\text { Jumlah } \\
\text { Skor }\end{array} \\
184\end{array}$} & \multirow{3}{*}{$\begin{array}{l}\begin{array}{l}\text { Rata- } \\
\text { Rata } \\
\text { Skor }\end{array} \\
\\
3,91\end{array}$} & \multirow{3}{*}{$\begin{array}{r}\text { Kategori } \\
\text { Penilaian } \\
\text { Setuju }\end{array}$} \\
\hline & & \multirow{2}{*}{5} & \multirow{2}{*}{4} & \multirow{2}{*}{$\begin{array}{l}3 \\
11\end{array}$} & \multirow{2}{*}{$\begin{array}{l}2 \\
4\end{array}$} & \multirow{2}{*}{1} & & & \\
\hline 1 & $\begin{array}{lrr}\text { Saya } & \text { menganggap } & \text { saya } \\
\text { tidak akan } & \text { mmiliki } \\
\text { kesempatan } & \text { untuk } \\
\text { dipromosikan } & \\
\end{array}$ & & & & & & & & \\
\hline 2 & $\begin{array}{l}\text { Saya menganggap gaji yang } \\
\text { diberikan kurang sesuai }\end{array}$ & 12 & 17 & 15 & 2 & 1 & 178 & 3,79 & Setuju \\
\hline 3 & $\begin{array}{l}\text { Saya merasa kesulitan } \\
\text { untuk memperoleh sumber } \\
\text { daya di Perusahaan (SDM, } \\
\text { Infomasi, dII) }\end{array}$ & 15 & 17 & 13 & 1 & 1 & 185 & 3,94 & Setuju \\
\hline 4 & $\begin{array}{l}\text { Saya merasa tidak mampu } \\
\text { menjalankan pekerjaan } \\
\text { sesuai SOP perusahaan }\end{array}$ & 15 & 15 & 14 & 3 & o & 183 & 3,89 & Setuju \\
\hline 5 & $\begin{array}{lr}\text { Saya tidak } & \text { selalu } \\
\text { mengantisipasi } & \text { tiap } \\
\text { kesalahan yang } & \text { saya } \\
\text { lakukan,sehingga } & \\
\text { mengancam pekerjaan saya }\end{array}$ & 15 & 14 & 13 & 4 & 1 & 179 & 3,81 & Setuju \\
\hline 6 & $\begin{array}{l}\text { Saya tidak berbuat sesuatu } \\
\text { untuk } \\
\text { ancaman yangantisipasi } \\
\text { kesalahan dan pelanggaran } \\
\text { yang saya lakukan atau } \\
\text { alami }\end{array}$ & 15 & 17 & 12 & 3 & o & 185 & 3,94 & Setuju \\
\hline 7 & $\begin{array}{l}\text { Saya merasa khawatir } \\
\text { kehilangan pekerjaan akan } \\
\text { mempengaruhi harkat dan } \\
\text { martabat karyawan }\end{array}$ & 14 & 18 & 12 & 2 & o & 183 & 3,89 & Setuju \\
\hline 8 & $\begin{array}{l}\text { Saya } \\
\text { pekerjaan yang diberikan } \\
\text { perusahaan dengan baik }\end{array}$ & 13 & 18 & 15 & o & 1 & 183 & 3,89 & Setuju \\
\hline 9 & $\begin{array}{l}\text { Saya merasa terancam } \\
\text { kehilangan pekerjaan yang } \\
\text { berasal dari lingkungan } \\
\text { internal }\end{array}$ & 13 & 17 & 14 & 3 & o & 181 & 3,85 & Setuju \\
\hline 10 & $\begin{array}{lr}\begin{array}{l}\text { Saya merasa khawatir akan } \\
\text { diberhentikan } \\
\text { melanggar }\end{array} \\
\text { perusahaan } & \text { jika } \\
\end{array}$ & 12 & 19 & 13 & 2 & 1 & 180 & 3,83 & Setuju \\
\hline 11 & $\begin{array}{l}\text { Saya tidak berdaya dalam } \\
\text { menghadapi keadaan yang } \\
\text { ada pada lingkungan kerja }\end{array}$ & 18 & 16 & 12 & o & 1 & 191 & 4,06 & Setuju \\
\hline 12 & $\begin{array}{lr}\text { Saya merasa } & \text { tidak berdaya } \\
\text { terhadap } & \text { peraturan } \\
\text { peraturan } & \text { yang } \\
\text { memberatkan } & \\
\end{array}$ & 13 & 18 & 14 & 1 & 1 & 182 & 3,87 & Setuju \\
\hline 13 & $\begin{array}{lll}\text { Saya gelisah dan } & \text { tidak } \\
\text { berdaya terhadap peristiwa- } \\
\text { peristiwa yang } & \text { akan } \\
\text { mempengaruhi kerja } & \text { saya } \\
\text { seperti dipecat } & & \\
\end{array}$ & 6 & 30 & 7 & 4 & 0 & 179 & 3,81 & Setuju \\
\hline & Jumlal & $\frac{\text { kor }}{\text { skor }}$ & & & & & $\begin{array}{l}2.373 \\
50.49\end{array}$ & $\frac{182,54}{3.88}$ & Setuju \\
\hline
\end{tabular}

Sumber : data primer, diolah (2019) 
Pada Tabel 3 dilihat bahwa seluruh pernyataan kuisioner dalam kategori setuju dengan skor rata-rata 3,88. Jawaban tertinggi pada pernyataan 11 dengan nilai rata-rata sebesar 4,06 yang menyatakan saya tidak berdaya dalam menghadapi keadaan lingkungan kerja. Sedangkan jawaban terendah pada pernyataan 2 nilai rata-rata sebesar 3,79 yang menyatakan gaji yang diberikan kurang sesuai.

Berdasarkan tabel 4 penilaian katagori seluruh pernyataan kuisioner dalam katagori setuju dengan skor rata-rata sebesar 3,81. Kriteria jawaban tertinggi terdapat dalam pernyataan 5 nilai rata-rata sebesar 3,94 yang menyatakan rasa diabaikan dan diasingkan oleh rekan kerja. Kriteria jawaban terendah pada pernyataan 4 nilai rata-rata sebesar 3,68 yang menyatakan sering mendapat teriakan, ejekan dan cemooh mengenai hasil pekerjaan.

\section{Tabel 4}

Kriteria dan Penilaian Jawaban Responden Terhadap Variabel Workplace Bullying

\begin{tabular}{|c|c|c|c|c|c|c|c|c|c|}
\hline \multirow{2}{*}{\multicolumn{2}{|c|}{ Pernyataan }} & \multicolumn{5}{|c|}{ Jawaban } & \multirow{3}{*}{$\begin{array}{c}\begin{array}{c}\text { Jumlah } \\
\text { Skor }\end{array} \\
178\end{array}$} & \multirow{3}{*}{$\begin{array}{l}\text { Rata- } \\
\text { Rata } \\
\text { Skor }\end{array}$} & \multirow{3}{*}{$\begin{array}{r}\begin{array}{r}\text { Kategori } \\
\text { Penilaian }\end{array} \\
\text { Setuju }\end{array}$} \\
\hline & & \multirow{2}{*}{$\frac{5}{8}$} & \multirow{2}{*}{$\frac{4}{26}$} & \multirow[b]{2}{*}{8} & \multirow[b]{2}{*}{5} & \multirow{2}{*}{$\frac{1}{0}$} & & & \\
\hline 1 & $\begin{array}{l}\text { Rekan saya cenderung } \\
\text { menyembunyikan informasi }\end{array}$ & & & & & & & & \\
\hline 2 & $\begin{array}{l}\text { Saya diperintahkan untuk } \\
\text { mengerjakan pekerjaan di luar } \\
\text { kompetensi saya }\end{array}$ & 10 & 23 & 11 & 2 & 1 & 180 & 3,83 & Setuju \\
\hline 3 & 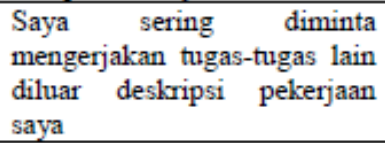 & 12 & 17 & 15 & 3 & 0 & 179 & 3,81 & Setuju \\
\hline 4 & $\begin{array}{l}\text { Saya sering mendapat } \\
\text { teriakan, ejekan dan cemooh } \\
\text { mengenai hasil pekerjaan } \\
\text { yang saya lakukan }\end{array}$ & 5 & 24 & 16 & 2 & 0 & 173 & 3,68 & Setuju \\
\hline 5 & $\begin{array}{l}\text { Saya merasa diabaikan dan } \\
\text { diasingkan oleh rekan kerja }\end{array}$ & 5 & 36 & 4 & 2 & 0 & 185 & 3,94 & Setuju \\
\hline 6 & $\begin{array}{l}\text { Atasan saya sering menyuruh } \\
\text { saya untuk mengulangi tugas } \\
\text { yang saya kerjakan tanpa } \\
\text { alasan yang jelas }\end{array}$ & 4 & 31 & 9 & 3 & 0 & 177 & 3,77 & Setuju \\
\hline 7 & $\begin{array}{l}\text { Atasan saya menunda } \\
\text { memeriksa hasil kerja saya } \\
\text { dengan alasan yang tidak } \\
\text { jelas, akibatnya pekerjaan } \\
\text { saya selanjutnya terhambat }\end{array}$ & 3 & 38 & 3 & 3 & 0 & 182 & 3,87 & Setuju \\
\hline 8 & $\begin{array}{l}\text { Saya sering dikritik tanpa } \\
\text { alasan yang jelas }\end{array}$ & 6 & 29 & 6 & 6 & 0 & 176 & 3,74 & Setuju \\
\hline 9 & $\begin{array}{l}\text { Saya diingatkan terus } \\
\text { menerus mengenai kesalahan } \\
\text { yang telah saya lakukan }\end{array}$ & 9 & 25 & 7 & 6 & 0 & 178 & 3,79 & Setuju \\
\hline 10 & $\begin{array}{l}\text { Saya sering mendengar gossip } \\
\text { tentang saya atau orang lain } \\
\text { beredar di tempat kerja }\end{array}$ & 10 & 22 & 13 & 2 & 0 & 181 & 3,85 & Setuju \\
\hline & Jumlah & & & & & & 1.789 & 178,90 & Setuin \\
\hline & Rata-rat & skor & & & & & 38,06 & 3,81 & . \\
\hline
\end{tabular}

Sumber : data primer, diolah (2019)

Berdasarkan Tabel 5 katagori seluruh pernyataan kuesiner termasuk dalam katagori setuju dengan skor rata-rata sebesar 3,59. Kriteria jawaban tertinggi pada pernyataan 3 nilai rata- 
rata sebesar 3,66 yang menyatakan lebih sering meninggalkan tempat kerja ketika jam kerja. Kriteria jawaban terendah pada pennyataan 5 nilai rata-rata sebesar 3,53 bahwa semangat kerja berkurang yang ditunjukkan penurunan pencapaian target.

Tabel 5

Kriteria dan Penilaian Jawaban Responden Terhadap Variabel Turnover Intention

\begin{tabular}{|c|c|c|c|c|c|c|c|c|c|}
\hline \multirow{2}{*}{\multicolumn{2}{|c|}{ Pernyataan }} & \multicolumn{5}{|c|}{ Jawaban } & \multirow{2}{*}{$\begin{array}{l}\text { Jumlah } \\
\text { Skor }\end{array}$} & \multirow{2}{*}{$\begin{array}{l}\text { Rata- } \\
\text { Rata } \\
\text { Skor }\end{array}$} & \multirow{2}{*}{$\begin{array}{l}\text { Kategori } \\
\text { Penilaian }\end{array}$} \\
\hline & & 5 & 4 & 3 & 2 & 1 & & & \\
\hline 1 & $\begin{array}{l}\text { Saya cenderung lebih sering absen } \\
\text { dengan berbagai alasan tertentu }\end{array}$ & 6 & 19 & 20 & 1 & 1 & 169 & 3,60 & Setuju \\
\hline 2 & $\begin{array}{l}\text { Saya mulai bosan dengan rutinitas yang } \\
\text { menoton }\end{array}$ & 3 & 23 & 19 & 2 & 0 & 168 & 3,57 & Setuju \\
\hline 3 & $\begin{array}{l}\text { Saya lebih sering meninggalkan tempat } \\
\text { kerja ketika jam kerja berlangsung }\end{array}$ & 5 & 23 & 17 & 2 & 0 & 172 & 3,66 & Setuju \\
\hline 4 & $\begin{array}{l}\text { Saya senang melakukan protes terhadap } \\
\text { kebijakan }- \text { kebijakan perusahaan } \\
\text { kepada atasan }\end{array}$ & 3 & 25 & 17 & 1 & 1 & 169 & 3,60 & Setuju \\
\hline 5 & $\begin{array}{l}\text { Semangar kerja saya mulai berkurang } \\
\text { seperti penurunan pencapaian target }\end{array}$ & 5 & 18 & 22 & 1 & 1 & 166 & 3,53 & Setuju \\
\hline \multicolumn{7}{|c|}{ Jumlah Skor } & 844 & 168,80 & \multirow{2}{*}{ Setuju } \\
\hline \multicolumn{7}{|c|}{ Rata-rata skor } & 17,96 & 3,59 & \\
\hline
\end{tabular}

Sumber : data primer, diolah (2019)

\section{Uji Asumsi Klasik}

\section{Uji Normalitas}

Berdasarkan Tabel 6 terlihat bahwa nilai Sig.(2-tailed) sebesar 0,200>0,05. Oleh sebab itu Ho tidak dapat ditolak. Hal itu berarti nilai residual terstandarisasi dinyatakan menyebar secara normal.

Tabel 6

Uji Normalitas

One-Sample Kolmogorov-Smirnov Test

\begin{tabular}{|c|c|c|}
\hline & & $\begin{array}{c}\text { Unstandardized } \\
\text { Residual| }\end{array}$ \\
\hline $\begin{array}{l}\text { N } \\
\text { Normal Parameters } \\
\text { Most Extreme Differences } \\
\text { Test Statistic } \\
\text { Asymp. Sig. (2-tailed) }\end{array}$ & $\begin{array}{l}\text { Mean } \\
\text { Std. Deviation } \\
\text { Absolute } \\
\text { Positive } \\
\text { Negative }\end{array}$ & $\begin{array}{r}47 \\
.0000000 \\
2.21643298 \\
.094 \\
.094 \\
-.084 \\
.094 \\
.200\end{array}$ \\
\hline
\end{tabular}

Sumber : Data primer, diolah (2020)

\section{Uji Multikolinearitas}

Uji mulikolinearitas bertujuan untuk menguji apakah model regresi ditemukan adanya korelasi antar variabel bebas (independen). 
Tabel 7

Uji Multikolinearitas

Coefficients $^{\mathrm{a}}$

\begin{tabular}{|c|c|c|c|c|c|c|c|c|}
\hline \multirow{2}{*}{\multicolumn{2}{|c|}{ Model }} & \multicolumn{2}{|c|}{$\begin{array}{c}\text { Unstandardized } \\
\text { Coefficients }\end{array}$} & \multirow{2}{*}{$\begin{array}{c}\text { Standardized } \\
\text { Coefficients }\end{array}$} & \multirow[b]{2}{*}{$\mathrm{t}$} & \multirow[b]{2}{*}{ Sig. } & \multicolumn{2}{|c|}{$\begin{array}{l}\text { Collinearity } \\
\text { Statistics }\end{array}$} \\
\hline & & $\mathrm{B}$ & Std. Error & & & & Tolerance & VIF \\
\hline 1 & (Constant) & 3.686 & 2.109 & & 2.375 & .019 & & \\
\hline & $\mathrm{X} 1$ & .089 & .037 & .301 & 2.380 & .012 & .684 & 1.463 \\
\hline & $\mathrm{X} 2$ & .257 & .064 & .507 & 4.008 & .000 & .684 & 1.463 \\
\hline
\end{tabular}

Sumber : data primer, diolah (2020)

Berdasarkan output pada coefficient terlihat bahwa nilai Tolerance Job Inscecurity (X1) dan Workplace Bullying (X2) sebesar 0,684, sedangkan nilai VIF (Varian Inflation Factor) variabel Job Inscecurity (X1) dan Workplace Bullying (X2) sebesar 1,463. Nilai TOL dan VIF variabel dalam kasus ini sama, maka pada model regresi yang terbentuk tidak terjadi gejala multikolinieritas

\section{Uji Heteroskedastisitas}

Berdasarkan Tabel 8 dapat diketahui bahwa pada model regresi tidak terjadi gejala heteroskesdastisitas. Hasil ini karena Sig. variabel Job Inscecurity (X1) terdapat absolut residual sebesar 0,815 > 0,05, variabel Workplace Bullying (X2) terdapat absolut residual sebesar 0,781 $>0,05$, maka pada model regresi yang terbentuk tidak terjadi gejala heteroskesdastisitas.

\section{Tabel 8}

\section{Uji Heteroskedastisitas}

Coefficients $^{\mathrm{a}}$

\begin{tabular}{|c|c|c|c|c|c|c|}
\hline \multirow{2}{*}{\multicolumn{2}{|c|}{ Model }} & \multicolumn{2}{|c|}{ Unstandardized Coefficients } & $\begin{array}{c}\text { Standardized } \\
\text { Coefficients }\end{array}$ & \multirow[b]{2}{*}{$\mathrm{T}$} & \multirow[b]{2}{*}{ Sig. } \\
\hline & & $\mathrm{B}$ & Std. Error & Beta & & \\
\hline 1 & (Constant) & 1.690 & 1.170 & & 1.445 & .156 \\
\hline & $\mathrm{X} 1$ & -.005 & .021 & -.043 & -.235 & .815 \\
\hline & $\mathrm{X} 2$ & .010 & .036 & 051 & .280 & .781 \\
\hline
\end{tabular}

Sumber : data primer, diolah (2020).

\section{Analisis Regresi Linear Berganda}

Tabel 9

Hasil Uji Regresi Linear Berganda Coefficients $^{\mathrm{a}}$

\begin{tabular}{|c|c|c|c|c|c|c|}
\hline \multirow{2}{*}{\multicolumn{2}{|c|}{ Model }} & \multicolumn{2}{|c|}{ Unstandardized Coefficients } & \multirow{2}{*}{$\begin{array}{c}\begin{array}{c}\text { Standardized } \\
\text { Coefficients }\end{array} \\
\text { Beta }\end{array}$} & \multirow[b]{2}{*}{$\mathrm{T}$} & \multirow[b]{2}{*}{ Sig. } \\
\hline & & $\mathrm{B}$ & Std. Error & & & \\
\hline \multirow[t]{3}{*}{$\overline{1}$} & (Constant) & 3.686 & 2.109 & & 2.375 & .019 \\
\hline & $\mathrm{X} 1$ & .089 & .037 & .301 & 2.380 & .012 \\
\hline & $\mathrm{X} 2$ & .257 & .064 & .507 & 4.008 & .000 \\
\hline
\end{tabular}

a. Dependent Variable: $Y$

Sumber : data primer, diolah (2020) 
Analisis regresi berganda dipilih untuk menganalisis pengujian hipotesis dalam penelitian ini. Berikut ini hasil analisis regresi berganda yang dilakukan dengan menggunakan program SPSS.

Dari persamaan diatas maka dapat dibuat persamaan regresi penelitian ini adalah :

$\mathrm{Y}=3,686+0,089 \mathrm{X} 1+0,257 \mathrm{X} 2+\varepsilon \mathrm{i}$

Interprestasi dari koefisien regresi :

$\beta 0=3,686$ secara statistik menunjukan bahwa Turnover Intention Karyawan (Y) akan meningkat sebesar 3,686 satuan dengan syarat variabel lain dalam penelitian ini yakni Job Inscecurity (X1), dan Workplace Bullying (X2) diasumsikan sama dengan nol.

$\beta 1=0,089$ secara statistik menunjukkan ada pengaruh positif dan signifikan antara variabel Job Inscecurity (X1) terhadap Turnover Intention Karyawan (Y) sebesar 0,089 yang artinya setiap terjadi (adanya) peningkatan Job Inscecurity sebesar satu satuan maka akan menyebabkan meningkatnya Turnover Intention Karyawan sebesar 0,089 satuan dengan syarat variabel lain diasumsikan sama dengan nol.

$\beta 2=0,257$ secara statistik menunjukkan ada pengaruh positif dan signifikan antara variabel Workplace Bullying (X2) terhadap Turnover Intention Karyawan (Y) sebesar 0,257 yang artinya setiap terjadi kenaikan (adanya) Workplace Bullying sebesar satu satuan maka akan menyebabkan meningkatanya Turnover Intention Karyawan sebesar 0,257 satuan dengan syarat variabel lain diasumsikan sama dengan nol.

\section{Analisis Determinasi}

Berdasarkan Tabel 10, koefisien determinasi yang ditunjukkan dari nilai $R$ Square sebesar 0,719. Hal ini berarti variabel (Y) dapat dijelaskan oleh dua variabel X1 dan X2 sebesar $71,90 \%$ sedangkan sisanya 0,281 atau $28,1 \%$ dijelaskan oleh variabel atau sebab - sebab lainnya di luar model penelitian.

Tabel 10

Hasil Uji Analisis Koefisien Determinasi

Model Summary

\begin{tabular}{|l|r|r|r|r|}
\hline Model & $\mathrm{R}$ & R Square & \multicolumn{1}{c|}{$\begin{array}{c}\text { Adjusted R } \\
\text { Square }\end{array}$} & $\begin{array}{c}\text { Std. Error of the } \\
\text { Estimate }\end{array}$ \\
\hline 1 & $.920^{\mathrm{a}}$ & .719 & .697 & 2.266 \\
\hline
\end{tabular}

Sumber : data primer, diolah (2020) 


\section{Uji Signifikan Parsial (Uji T-Test)}

Uji statistik T-Test pada dasarnya menunjukkan seberapa jauh pengaruh satu variabel penjelas/independen digunalan untuk menguji hipotesis $\mathrm{H} 1$ dan $\mathrm{H} 2$, yaitu pengaruh secara parsial variabel Job Inscecurity dan Workplace Bullying terhadap Turnover Intention Karyawan Seminyak Garden Hotel \& Pool.

Tabel 11

Hasil Uji Signifikansi Parsial (Uji T-Test)

Coefficients $^{a}$

\begin{tabular}{|c|c|c|c|c|c|c|}
\hline \multirow{2}{*}{\multicolumn{2}{|c|}{ Model }} & \multicolumn{2}{|c|}{ Unstandardized Coefficients } & $\begin{array}{c}\text { Standardized } \\
\text { Coefficients }\end{array}$ & \multirow[b]{2}{*}{$t$} & \multirow[b]{2}{*}{ Sig. } \\
\hline & & $\mathrm{B}$ & Std. Error & Beta & & \\
\hline \multirow[t]{3}{*}{1} & (Constant) & 3.686 & 2.109 & & 2.375 & .019 \\
\hline & $\mathrm{X} 1$ & .089 & .037 & .301 & 2.380 & .012 \\
\hline & $\mathrm{X} 2$ & .257 & .064 & .507 & 4.008 & .000 \\
\hline
\end{tabular}

a. Dependent Variable: $Y$

Sumber : data primer, diolah (2020)

Dari uji t-test pada Tabel 11 maka dapat dikemukakan hasil sebagai beriku t :

1. Job insecurity (X1) menunjukkan nilai $t_{\text {hitung }} 2,380>t_{\text {tabel }} 1,684$ dengan signifikansi $0,012<$ 0,05 maka dapat dikemukakan hasil bahwa hipotesis 1 (H1) yang menyatakan job insecurity berpengaruh positif dan signifikan dapat diterima. Hasil penelitian ini juga mendukung penelitian sebelumnya yang dilakukan oleh Setianingsih (2013) yang menyatakan bahwa Job Inscecurity berpengaruh signifikan terhadap Turn Over Karyawan.

2. Workplace bullying (X2) menunjukkan nilai thitung 4,008 $>t_{\text {tabel }} 1,684$ dengan signifikansi $0,000<0,05$ maka dapat dikemukakan hasil bahwa hipotesis $2(\mathrm{H} 2)$ yang menyatakan work place bullying berpengaruh positif dan signifikan terhadap turnover intention dapat diterima. Hasil penelitian ini juga mendukung penelitian sebelumnya yang dilakukan oleh Wicaksono (2014) yang menyatakan bahwa Workplace Bullying berpengaruh terhadap Turnover Intention Karyawan.

\section{Uji Signifikan Simultan (Uji F-Test)}

Uji statistik $\mathrm{F}$ menunjukkan apakah semua variabel independen dalam model mempunyai pengaruh secara bersama - sama terhadap variabel dependen.

Tabel 12

Hasil Uji F-Test

ANOVA $^{\mathrm{a}}$

\begin{tabular}{|ll|r|r|r|r|r|}
\hline Model & & Sum of Squares & Df & Mean Square & F & Sig. \\
\hline 1 & Regression & 243.936 & 2 & 121.968 & 23.748 & .000 \\
& Residual & 225.978 & 44 & 5.136 & & \\
& Total & 469.915 & 46 & & & \\
\hline
\end{tabular}

a. Dependent Variable: $Y$

Sumber : data primer, diolah (2020) 
Hasil uji F-test pada Tabel 12 menunjukkan bahwa nilai $F_{\text {hitung }}$ 23,748 $>F_{\text {tabel }}$ 3,23 dengan nilai signifikansi $0,000<0,05$ maka dapat dikemukakan bahwa job insecurity dan workplace bullying secara simultas berpengaruh positif dan signifikan terhadap turnover intention. Dengan demikian hipotesis $3(\mathrm{H} 3)$ yang menyatakan bahwa Job Inscecurity (X1) dan Workplace Bullying (X2) berpengaruh terhadap Turnover Intention Karyawan (Y) dapat diterima.

\section{Simpulan Dan Saran}

\section{Simpulan}

Berdasarkan data yang diperoleh dari hasil analisis dapat ditarik kesimpulan sebagai berikut :

1. Job Inscecurity berpengaruh positif dan signifikan terhadap Turnover Intention Karyawan Seminyak Garden Hotel \& Pool. Hal ini dapat dibuktikan dengan thitung = 2,380 $>$ ttabel $=1,684$. Berarti semakin tinggi job insecurity maka semakin tinngi pula tingkat turnover intention.

2. Workplace Bullying berpengaruh positif dan signifikan terhadap Turnover Intention Karyawan Seminyak Garden Hotel \& Pool. Hal ini dapat dibuktikan dengan thitung 4,008 $>$ ttabel $=1,684$. Berarti semakin tinggi workplace bulllying maka semakin tinngi pula tingkat turnover intention.

3. Job Inscecurity dan Workplace Bullying berpengaruh positif dan signifikan terhadap Turnover Intention Karyawan Seminyak Garden Hotel \& Pool. Hal in dapat dibuktikan dengan Ftabel $=3,23<$ Fhitung $=23,748$. Berarti semakin tinggi job insecurity dan workplace bulllying maka semakin tinngi pula tingkat turnover intention.

\section{Saran}

1. Berdasarkan hasil penelitian, secara parsial Job Inscecurity perlu dikendalikan agar dapat menurunkan Turnover Intention Karyawan. Berdasarkan nilai rata-rata pada pernyataan no 11 dengan nilai rata-rata sebesar 4,06 yang menyatakan bahwa Saya tidak berdaya dalam menghadapi keadaan yang ada pada lingkungan kerja. Maka diharapkan, manajemen hotel dapat mengendalikan keadaan yang terdapat pada lingkungan kerja hotel seperti menciptakan lingkungan kerja yang aman dan nyaman sehingga dapat terhindar dari niat keluarnya karyawan dari perusahaan.

2. Berdasarkan hasil nilai rata-rata jawaban pada pernyataan no. 5 nilai rata-rata sebesar 3,94 yang menyatakan Saya merasa diabaikan dan diasingkan oleh rekan kerja. Disarankan kepada manajemen perusahaan untuk selalu memberikan peluang terhadap karyawan untuk mempererat hubungan sesama rekan kerja, menciptakan lingkungan 
kerja yang relatif lebih nyaman bagi karyawannya, mengembangkan keterampilan dan kemampuan pada karyawannya agar karyawan lebih meningkatkan kinerjanya sehingga usia perusahaan lebih besar atau lebih panjang dalam mencapai target yang ditentukan organisasi.

3. Bagi peneliti selanjutnya dengan berbagai keterbatasan penelitian ini, diharapkan peneliti selanjutnya akan lebih mendalam mengkaji perihal pengaruh Job Inscecurity dan Workplace Bullying terhadap Turnover Intention Karyawan agar hasilnya lebih akurat dan dapat digeneralisir untuk semua perusahaan ataupun organisasi. Selain itu, peneliti selanjutnya juga diharapkan untuk mengkaji variabel-variabel lain meningat koefisien determinasi yang dihasilkan sebesar $71,90 \%$ sedangkan $28,1 \%$ terdapat variabel lain yang tidak termasuk dalam model penelitian yang kemungkinan berpengaruh terhadap Turnover Intention karyawan.

\section{Daftar Pustaka}

Adewale, Adekiya, A 2015. Perceived Job Insecurity: Its Individual, Oganizational and Social Effect. Europen Scientific Journal December 2015/SPECIAL/edition Vol.1 ISSN : 1857-7881.

Akgunduz, Yilmaz dan Gamze Eryilmaz. 2018. Does Turnover Intention Mediate the Effects of Job Insecutiry and Co-worker Support on Social Loafing?. International Journal of Hospitality Management, Vol. 68, pp. 41-49

Avci, N., Kucukusta, D. 2009. The Analysis of the Relationship Among OrganizationalLearning, Organizational Commitment and Tends to Leave in Hotels. Journal of Tourism Research, Vol. 20, No. 1, pp. 33-44

Çelik, M dan A. Çıra, 2013. The Mediating Role of Work Overload on the Effects of Organizational Citizenship Behavior on Job Performance and Turnover Intention. Ege Academic Review, Vol. 13, No. 1, pp. 11-20

Demir, C., Çolakoğlu, Ü.,Güzel, B. (2007). Relationship Between Employee Turnover and The Location of Hotels: The Case of Kuşadası and Izmir in Turkey. Journal of Yasar University, 2 (5): 477-487.

Emiroglu, Gegum Dilara., Orhan Akova., dan Haluk Tanriverdi. 2015. The Relationship Between Turnover Intention and Demographic Factor in Hotel Business: a Study at Five Star Hotel in Istanbul. Social danBehavioral Science, Vol. 207, pp. 385-397.

Faldetta, G., Fasone, V., Provenzano, C. (2013). Turnover in the Hospitality Industry: Can Reciprocity Solve the Problem. Revista de Turismo y Patrimonio Cultural, 11(4):583-595.

Glambek, Mats, Matthiesen, S.B., Hetland Jorn. Dan Einersen, Stale.2014. Workplsce Bullying as an Antecedenr to Job Insecurity and Intention to Leave: a 6-month Prospectictive Study. Human Resources Management Journal. Vol.24, No.3. 
Hanafiah, Mohammad. 2014. Pengaruh Kepuasan Kerja Dan Ketidakamanan Kerja (Job Insecurity) Dengan Intensi Pindah Kerja (Turnover Intention) Pada Karyawan PT. Buma Desa Suara Kecamatan . Sambaliung Kabupaten Berau. E- Jurnal Psikologi, 1(3) : 303-312.

Heryanda, Komang .Krisna. 2019. The Effcet of Job Insecurity on Turnover Intention Through Work Satisfaction in Employee of PT Telkom Access Singaraja. International Journal of Social Science and Business, Vol. 3, No. 3, pp. 198-205

Ismal, H.2015. Job Insecurity, Burnout and Intention to Quit, International Journal of Academic Reseacrch in Business and Social Sciences.

Kang, D.S.,Jeef, G., And Daewon, K. 2012. Responses To Job Insecurity The Impact On Discretionary Extra-Role And Impression Manajement Behaviours And The Moderating Role Of Employability. Journal International, 17(4): 314-332.

Kekesi, Elias Kodjo, dan Collins Badu Agyemang. 2014. Perceived Job Insecurity and Psychological Distress: The Moderating Role of Work Values. International Journal of Management, Economics and Social Sciences, 3(1), pp: 18-35.

Kim, K., Jogaratnam, G. (2010). Effects of Individual and Organizational Factors on Job Satisfaction and Intent to Stay in The Hotel and Restaurant Industry. Journal of Human Resources in Hospitality \& Tourism, 9: 318-339.

Lam, T., Lo, A., Chan, J. (2002). New Employees' Turnover Intentions and Organizational Commitment in The Hong Kong Hotel Industry. Journal of Hospitality \& Tourism Research, 26 (3): 217-234.

Mete, Edip Sabahatin., Sokmen, Alev. 2016. The Influence of Workplace Bullying of Employee's Job Performance, Job Satisfaction, and Turnover Intention in a New Established Private Hospital. International Review of Management and Bussiness Reseach. Vol.5.

Minanti Puput, 2015 "Pengaruh Job Insecurity, Komitmen Organisasi dan Kepuasan Kerja Terhadap Turnover Intention melalui Stress Kerja Pada Sopir P.O Citra Wisata Mandiri (CWM) Jember". Fakultas Ekonomi Juruan Manajemen. Universitas Jember.

Nasution, Wendi Ansuri 2009. Pengaruh Kepuasan Kerja Terhadap Intensi Turn Over Pada Call Center Telkomsel Di Medan, Vol 4, No.1.

Oade, Aryanne (2009). Managing Workplace Bullying. Palgrave Macmillan, New York.

Ocel, Hatem. dan Aydin, Ordhan. (2012). Workplace Bullying and Turnover Intention: The Moderating Role of Belief in a Just World. International Journal of Business and Social Science. Vol. 3, No. 13.

Rai, Arpana., dan Upasna A. Agarwal. 2016 Workplace Bullying: A Review and Future Research Direction. South Asian Journal of Management, Vol. 23, No. 3

Salin, D. (2003). Ways of explaining workplace bullying: A review of enabling, motivating and precipitating structures and processes in the work environment. Human Relations, 56(10), 1213-1232. 
Suciati, Andi Tri Haryono, \& Maria Magnelia Minarsih .2015. Pengaruh Job Insecurity dan Stress Kerja Terhadap Turnover Intention Pegawai pada Karyawan PT.Berkat Abadi Surya Cemerlang Semarang (HO)". Jurnal Manajement Universitas Pandanaran, 1 (1), pp: 1-2.

Yahaya, A., T. C. Ing., Goh Mo Lee., N. Yahaya., Y. Boon., S. Hashim., dan Suhaila Taat. 2012. The Impact of Workplace Bullying on Work Performance. Archives Des Sciences, Vol. 65, No. 4.

Yang, J.T. (2008). Effect of Newcomer Socialisation on Organisational Commitment, Job Satisfaction, and Turnover Intention in The Hotel Industry. The Service Industries Journal, 28 (4): 429-443 